\title{
Ethics of agriculturalists
}

\author{
MN Paudel ${ }^{*}$
}

\begin{abstract}
Agronomy is the mother of agriculture and it is also synonymous to agricultur as well. Therefore, agronomy in general term in this article not only limits to the core discipline of agronomy and agronomists but also it entails the whole sphere of agriculture and agriculturists as well. Nonetheless, readers are humbly urged to take ethics of agronomists as the ethics of agriculturists for this is the agronomy journal's article which is meant for agronomists in general perspectives. It has been mentioned in this paper that what are the ethical boundaries of agriculturists in professional capacity. The paper also describes what the ethical issues with respect to agronomist as a researcher and extensionist are entailing while executing their duty. Pressures have been brought to bear upon farming and those who serve it in any capacity to widen the list of tasks to which agriculture should be devoted. At one time, the role of agriculture was to produce food, but now many people expect agriculture to be carried out in an environmentally friendly way that maintains the rural economy. We now speak of multifunctional agriculture. One tool sometimes used to press those demands is an appeal to ethics. This appeal can appear to suggest that agriculturalists have been ethically negligent. Every agricultural ethicist knows by experience how poorly received that suggestion is. Agriculture is a vocation or profession that prides itself on the unquestionable value, even nobility, of its work. Whereas agronomists should be engaged for number of works in day to day life involving social justification in farming, soil fertility and sustainability, soil conservation, rural living condition, farming and environment, healthy and nontoxic food production to the masses in an affordable manner, and so on and so forth. Above all, there is a big morale of agriculturist to save Mother Nature for our future generation tailored with multinational companies, engaged in agriculture, which have big say in generating and disseminating agro-technologies which are mooted to profit making and patenting agro biodiversity. This paper sheds lights in all such issues and aware agriculturists if it is being done ethically on the part of agriculturists/agronomists. Also the paper cites what are the ethical concerns of agriculturists to make their profession ethically sound that include honesty, integrity, fairness, and service to the clienteles in question.
\end{abstract}

Key words: agriculturist, agronomist, ethics

\footnotetext{
* Outreach Research Division, NARC, Khumaltar, mnpaudel@yahoo.com
} 


\section{Introduction}

The intension of this article is to help all agriculturalists, but especially agronomist who are working as researchers and extensionists by which they feel comfortable using ethics in handling the multiple and often conflicting demands that sectors of the public press on agriculture. Not much has been written about the ethical dimensions of agricultural professionals what their every day tasks for research and development are. Most of the ideas presented here are relevant to other professionals involved for food and agriculture as well. Agricultural professionals may have not been taught about professional ethics in institutions where they developed their careers. Therefore, from ethical point of view agronomists do what they feel right personally. This article is based on the review of papers presented by some renowned agronomists who thought that without a clear-cut ethical concern it is very difficult to carry out day today works. Aside from this, the author is guided conditions of his unique genetics, cultural background, upbringing, education, cross cultural adjustment, and experiences. This paper briefly reiterates what agronomists should do as their duty ethically so that their profession is directed towards the welling being of Mother Nature in general and living beings in particular.

Ethics as a process by which we distinguish between right and wrong behavior as well as referred to as a moral philosophy (Sparks, 1997). The concept of bad and good are different from right and wrong. Thus ethical behavior and unethical behavior can also lead to both good and bad consequences. Ethical describes moral approval in accord with some approved standard or code while unethical describes behavior which does not comply with accepted standard or codes. According to Sparks (1997) ethics are categorized into following:

\section{Personal and group ethics}

Each of us has a personal code of ethics how well they conform to code of ethics and behavior of various groups with which we identify. To some extent ethical and unethical behavior are learned behaviors such as our past experiences including early childhood experiences.

\section{Scientific misconduct}

Questionable scientific practices such as failing to retain important data for a reasonable period of time, maintaining inadequate research reports, denying peers reasonable access to materials or data supporting published papers, inadequately supervising research subordinates, exploiting them, and several others. Some of the other misconduct include unethical but not unique to science such as sexual harassment, misuse of funds, and vandalism of research facilities. 


\section{Practical principle of ethical behavior}

Keys of practical principle of ethical behavior include honesty, integrity, fairness, and service. Honesty is the quality of truthfulness. Seng (1990) identifies that telling the truth as a simple but profound strategy for achieving goals. Integrity broadens the concept of honesty to include the context in which honest or dishonest behavior occurs. You have integrity if you are honest when you will likely suffer bad consequences from being honest and/or you are unlikely to suffer bad consequences from being dishonest, perhaps because you will not be found out. Fairness involves treating other people fairly and not seeking to gain unfair advantages. Obviously fairness has dimension of equal treatment, equal opportunity and level playing. Agronomist generally values the science in the service of mankind (Holt, 1989). The concept of service as ethical behavior seems consistent with utilitarian approach to ethical decision making and with seeking to optimize benefit.

\section{Objective}

The major objective of this paper is to share professional ethics of agronomist with peer groups however the specific objectives are :

- to share what is ethical and unethical among agronomists while executing agricultural profession

- to know what are the ethical issues for researchers and extension people and

- to become aware not to do unethical jobs in the days to come.

\section{Methodology}

This is a desk work carried out by consulting available literatures thorough printed and electronic media. Consultation with senior professionals and experiences of the author are also shared widely.

\section{Discussions}

Discussions on ethics for agronomist consist of vast pool of subject matters. However, emphasis will be given for context most related to research and development aspect of pertinent field concerned. These include:

\section{Ethics of choosing research subject matter}

Sustainable agriculture movement played a key role in sensitizing agronomists to ethical issues in research and development. Agronomists were criticized by people who thought they were unduly influenced by private sponsor of research, especially when such sponsors were suppliers of inputs for production, including fertilizers, pesticides, seeds etc. Agronomists falsified or contrived data to please their sponsors and assured continued support. Such behavior would be unethical (Sparks, 1997). 


\section{Ethical dimension of agricultural theme}

Thompson (1988) identifies that productivity as the ethical themes of traditional/ conventional agriculture research while critics argues that new technology is developed and implemented in conventional agriculture without sufficient concern for its externalities, that is, its potential effects on environment, international justice, and agrarianism. Most researchers would agree that in many research situations it is impossible or impractical to evaluate all the possible externalities.

\section{Resolving ethical problem}

The ethical problem arises when a new technology works to improve conditions within one so called ethical theme but causes harm in the context of one or more other themes. To prevent this by precluding certain areas of research, however, prevents both good and bad outcomes. Often, the extent of good and bad cannot be estimated accurately until much of the research is accomplished. The appropriate response to this dilemma is to internalize as many as possible and practical of the externalities.

\section{Ethics in the conduct of research}

It is important to know how an agronomist develops and tests a hypotheses, marshals data, draws and reports inferences, engages in rational discourses, and works with colleagues and students in an ethical manner?

\section{Selecting topics for research}

Scientists embark on specific research efforts because they are interested in the subject matter, have expertise, wish to gain personal rewards etc. The decisions are conditioned by employment opportunities and availability of resources as well as each person letting his/her own ethical perceptions guiding these decisions.

\section{Designing experiments}

The more creative and knowledgeable scientists are the more likely they are to generate hypotheses that depart from the current paradigm. It is important for scientists to design experiments that will disprove their hypotheses if they are not true. Only if a hypothesis is not proven false by rigorous experimentation it is ethical for the scientist to promote it as a new paradigm.

\section{Collecting and reporting data}

It is generally accepted that fabrication and falsification of data constitute unethical behavior, except in special situation such as espionage. In reports data should be accurately represented so that readers are not misled. The more a scientist knows about the subject matter of an experiment, the easier to fabricate or falsify a data without being detected. It is 
unethical for an investigator to provide only data that support a certain hypotheses if he/she collected other data. There are statistical techniques that accommodate missing data without changing variants estimates. Statistical techniques should not be used to deal with outliers.

\section{Analyzing data}

Most agronomical data are subject to statistical analysis. With statistical information others can decide whether they think an investigator's conclusions and inferences are appropriate. Typically agronomists test hypotheses at $\mathrm{P}=$ probability of type one error $=0.05$. Researcher may perform various transformations so that data confirm more closely to the assumption of normality associated with many standard analytical procedures which are not unethical. Statistics can be used to misled, either intentionally or unintentionally. It is obviously unethical to use statistical anomalies to misled people deliberately.

\section{Drawing and reporting inferences}

Technically inferences drawn from an agronomic experiment only apply to the materials and conditions of that experiment. At the same time, it is usually impractical to test hypotheses with all possible materials and under all possible conditions.

\section{Establishing and maintaining credibility}

When a researcher is competent, professional, ethical, and intellectually honest in measuring, recording, analyzing, and presenting the results of experiments and inferences drawn from them, he/she establishes credibility and contributes to the credibility of his/her organization. Without credibility, neither scientist nor their organizations can function effectively.

\section{Intellectual property rights}

Increasingly, public institutes and agencies are expanding and improving systems to identify and protect intellectual property generated in their research operations. This presents a significant cultural as well as administrative change in many public and private institutions. Transferring intellectual property to the public domain, thus making it freely available to publics is not always in the public's best interest. It is therefore necessary to give some individual or group proprietary access to intellectual property. The management including sale and licensing, of intellectual property involves several ethical issues which are listed below:

\section{Patent and copy right}

It is illegal and unethical to commercialize patented material or duplicate, disseminate, or commercialize copy right intellectual property without the permission of the owner of the patent or copy right. This unethical behavior is similar to plagiarism. 


\section{Ethics and trade secret}

When dealing with trade secrets, the ethical course of action is not always clear. The principle is simple! Do not take things that do not belong to without permission. To a large extent, we depend on scientist's honesty and integrity to resolve the issues.

\section{Non disclosure agreement}

In order to enable useful exchange of proprietary information between organizations, it may be necessary for those participating in a discussion to sign nondisclosure agreements.

\section{Ethical treatment of animals in agronomic research}

Animals are used in agronomic research, especially in grazing and feeding trials, metabolism and toxicity trials, and behavioral studies involving agronomic materials. There is a need to increase productivity of animal operations and improve quality, safety, affordability, and convenience of animal product; we will no doubt continue to conduct research involving animals. The objective of most animal research conducted by or with agronomists is to improve crop as feed for animals, improve performance of animals consuming crops, or improve consumer products derived from animals that consume crops. Measures should be taken to minimize pain and discomfort and maximize animal well being in each experiment without compromising the validity of the experiment design. It definitely involves refraining from unnecessary harass treatment of animals. Animals should be treated most humanely while on the experiment.

\section{Ethics and competition}

Agronomists constantly encounter situations involving competitions. The competition is usually for resources, but may be for recognition, prestige, fame, self satisfaction, and other intangibles. We live in a hierarchy of competition in which individuals compete for resources with each other within their departments or other organizational units and even so called non profit organizations compete vigorously for resources. Competition can be very destructive, as in war and can be very constructive, as in competition to serve clients and costumers better. In a competitive framework, ethical behavior involves "playing fair" which is predetermined by rules and protocols. Ethical behavior for agronomists involves recognizing when it is appropriate to compete and when to cooperate.

\section{Issues associated with technological transfer}

Many agronomic researchers are also agent of technology transfer and face various ethical issues. As technology becomes more complex, users may rely more heavily on information from various technology transfer agents and be more vulnerable to the agents' mistake. Agronomists should provide information and assistances as honestly, thoroughly, and 
objectively as possible. They should not portray their knowledge as being greater than it is. Agronomists should follow following guidelines with respect to technology transfer:

\section{Transfer agents' responsibility}

Technology transfer agents bear responsibility, either actual or perceived, for the outcome when clients follow their recommendations. Limitations on responsibility and liability should be discussed and agreed on before a client accepts and acts on the recommendation of an agent. Suppliers, agents, and clients should participate honestly and fully on bad outcome situation.

\section{Testing and comparing product and practices}

Agronomists often test and compare alternative, competing products and practices. Unbiased competition carried out under the wide range of conditions usually encountered in agricultural situations, play a very important role in helping practitioners select the best combination of product and practices for agricultural system. Research reports should accurately and thoroughly depict the results of tests and comparisons. They should describe any circumstances that might render results unreliable or invalid. It is unethical for agronomist to falsify or fabricate test data in order to cause test and comparisons to favors one or the other of the items being compared. It is also unethical for researchers to misrepresent their ability and capacity to conduct tests and comparisons.

\section{Advocating products and practices}

It is ethical for private sector researchers to advocate their firms' products and services as long as they do not misrepresent them. It is clearly unethical for public researchers to advocate inferior products or practices in order to obtain kick back or other payments or rewards.

\section{Ethics of consultancy}

Consultants' works in the same ethical environment face the same ethical decisions and dilemmas as public sector scientists and extension people. Several of the ideas expressed in the technology transfer section apply for consultants. Consultants are obligated to function in the best interest of their clients and to provide value in return for compensation. It is also unethical for consultants to recommend that their clients engage in unethical behavior.

\section{Ethical in research and administration}

Administrative issues are important because they often directly affect people's career and life. Administrators are interested with other people's money and careers and are expected to manage them ethically. Ethics for agronomists involved in administration are as follows: 


\section{Ethical hiring and termination}

It is in the best interest of both public and private institutions and organizations to attract and retain best employees. The process of attracting, hiring, and retaining outstanding people is a competitive activity. It is ethical to compete vigorously within a system of rules and/or codes that establish the boundaries of ethical behavior. It is unethical to misrepresent a position to a potential employee or to make promises of future support or other conditions or deliberately and dishonestly undermine the efforts of competitors. It is sometimes necessary to terminate employment of an employee because of wrong doing or perceived deficiency in his/her performance. The process of termination should be as humane as possible. Harassment by employers and employees is clearly unethical.

\section{Nurturing scientist}

It is useful and practical for organizations that hire people into what are expected to be permanent positions to nurture their careers. Nurturing in agronomic research is an ongoing process in which employee becomes well informed about what they have to do to meet expectations of peers, administrators, and other decision makers.

\section{Fair evaluation}

Agronomists working as administrators often find themselves in position in which they must evaluate the performance of others or be evaluated themselves. Important decisions including hiring and termination, promotion and tenure, and salary increments, include evaluations. The important evaluations are as follows:

\section{Activity reports}

People being evaluated often are asked to submit report of their activities. They should be informed as to what criteria will be used to evaluate the reports. It is unethical to misrepresent performance on such reports or to wrongly take credit for accomplishments of others. The reports should be thorough, honest, and timely.

\section{Letter of recommendation, support, and evaluation}

Requests come from applicants and candidates for positions, promotions, and tenure, and award and from the people who are offering the positions, awards, university admission etc. Candidates hope the letter will portray their cases in the best light, emphasizing their strong points. It is unethical to deliberately misrepresent or slant information in a letter of recommendation, either to favor or disfavor the candidates or to influence a competition in favor of or against some other candidate. Author of such letter should be as honest and objective as possible, regardless of their relationship regardless with the person being evaluated. They should portray their knowledge of the person accurately, especially not claiming to know more than they know. 


\section{Promotions documents and decisions}

Those who prepare promotion documents bear a heavy ethical responsibility both to candidates for promotion and to the institutions or organizations. They are obligated to present a thorough, well-documented case, which may or may not be supportive of promotion. Authors of promotion documents need to proofread carefully, adhere to format specifications, and provide clear comments, well written narrative, where such is required.

\section{Job application}

It is unethical for candidates to misrepresent their education and experiences. When there are many qualified applicants for a position, perspective employers tend to scrutinize applications more closely, looking for anything that might help them decide among candidates. Unfortunately, this scrutiny tends to focus on negative attributes which in turns should not be the selecting criteria.

\section{Evaluating administrators/managers}

Many organizations have process for evaluating administrators periodically. Those being surveyed are obligated to answer survey question as truthfully, thoughtfully, accurately, and objectively as possible. It is clearly unethical for an individual or group to use periodic review as a mechanism for launching a personal dispute against an administrator/manager. Likewise, it is unethical for a person being evaluated to provide false information or to otherwise misrepresent his/her performance.

\section{Equity and merit}

Administrators/managers are often faced with balancing consideration of equity and merit. The ethical course of action for administrators is to make sure people being evaluated know what criteria to judge merit. The criteria should be applied uniformly, fairly, and consistently. The interest of organizations' clients, customers and constituent should be taken into account.

\section{Honest communication with constituents}

Administrators often need to portray their organization to groups of constituents. Sometimes an administrator is a "true believer" i.e., really convinced that the organization is exceptionally good. This may be true or it may be that the administrator is too emotionally involved with the organization to make objective judgments about it. It is unethical to provide false or misleading information about one's organization. If there are problems within the organization or with the organizations' relationship, it is best to share those problems with clients or constituents and, whenever possible, enlist their aids in solving them. Relationships between organizations and their constituents should be characterized by ethical behavior, including honesty, fairness, and service. 


\section{Conclusion}

Role of agronomist in war and peace is equally important. In war their role is to grow crops for feeding people not to starve of them and take care about the equity and supply of foods while in peace there comes a role of increasing productivity and boost production per unit area so that glut of production for sustaining lives and commercializing agro-products take place smoothly. There are times when agronomists should involve judging what is right and wrong with respect to evaluating agriculture inputs and products brought into markets by some multinational company and big house whose aim is centered for profit making. Such organizations, presently, are deeply mooted into patenting agro-products and at the same time they are concentrated to capture natural flora and fauna in the name of patenting rights. In such situations, agriculture professional should strongly favor for the rural masses who are conserving these agro-biodiversity from the time settled agriculture was started at the dawn of civilization. This has created a dilemma as to which is ethical and unethical so as to give professional judgments for agriculturalists. There are cases when agronomists and extension people have been advocating such commercial products without thinking of professional ethics. Such issues include commercialization of genetically modified organisms (GMOs), Bt variety of crops, agro-chemicals (seeds, pesticides, hormones, fertilizers), new crop varieties (hybrid, OPV, and local but modified genotypes) so on and so forth. We have experienced, in some way or other way, some time agriculture professionals have been engaged for promoting such products with a meager hope of getting some personal incentives such as kickbacks, reward or some form of other personal motivations. It is against the ethics of professionals to involve in such activities unless benefits of products from these big commercial houses have been established by scientific standards. The consequences of such products to the ignorant masses such as allergic reaction of the products, their negative effects on biodiversity conservation, failure of crops bearings grain/fruit, effect on soil microorganisms and, underground water pollution, and sustainability of natural resources, resistance to insect pest and diseases, introduction of new pest and diseases, and above all destruction of Mother Nature is of unforgivable consequences. Agriculture professional should finally bear the impact of such devastating concerns brought about without taking into consideration of scientific paradigms for such issues. Of course, in such circumstances the consequences rest for unethical decisions of agriculture professional as well.

\section{Acknowledgements}

The author expresses his gratitude to the renowned agriculturists/agronomists who toiled their efforts to document ethical issues of agriculturalists alias agronomists. $\mathrm{He}$ is also indebted to the seniors whose statements have been cited here as a guide for fellow agriculturists thereby agriculturists are bound to follow contemporary code of conduct while carrying out day today duty. Also he puts his submission for not wholly citing their views in this article and wished that the rest of ethical issues would be covered by fellow agronomists in the days ahead. 


\section{References}

Sparks, DL. 1997. Practical ethics in agronomic research. Advances in Agronomy 60: 149-190.

Holt, DA. 1989. Presidential address: Change and Stability in the American Society of Agronomy. Agron .J.81:141/144.

Seng, PM. 1990. The fifth discipline Doubleday, Newyork as cited by DL Sparks in Advances in Agronomy 60: 149-190.

Thompson, PB. 1988. Ethical dilemmas in Agriculture: The Need for Recognition and Resolution. Agric. Hum.Values 5: 4-15. 